\title{
SISTEMA DE IRRIGAÇÃO LOCALIZADA AUTOMATIZADA
}

Amanda Neves Gomes - amanda_neves_@hotmail.com Fabiana Gomes de Araujo - fabianaengproducao@gmail.com

Letícia da Silva Silvano - leticiasilvano55@gmail.com Marina Ferreira Rodrigues - marinaengprod@gmail.com Zarur de Oliveira Silvano - zarurs@ yahoo.com.br

RESUMO: A aplicação da tecnologia é utilizada cada vez mais no setor agrícola, hoje em dia estão sendo empregados muitos estudos tencionando o manejo e ampliar a produtividade das culturas. A proposta deste projeto foi de pesquisar e compreender os conceitos de irrigação localizada automatizada, plataforma arduino e o emprego de sensores para a fiscalização de grandezas físicas. Com o intuito de unificar os conceitos estudados e criar um protótipo de um sistema de irrigação localizado automatizado usando as três tecnologias, conseguindo assim arquitetar um produto de baixo custo, preciso e acessível. Hoje no Brasil existem várias tecnologias disponíveis apontada para a agricultura, apesar disso são tecnologias de alto custo que precisam de grande investimento fazendo com que agricultores de pequeno e médio porte não possuam total aquisição a essas novas maneiras de trabalho. Atualmente a irrigação vem sendo uma das tecnologias mais empregadas por agricultores, pois independente da circunstância de chuvas ou não, assegura aos produtores uma colheita uniforme e diminuindo os riscos de perdas por falta de água. Manuseando as tecnologias estudas foi realizado um protótipo de sistema de irrigação localizada automatizada, de modo com que os sensores colhiam as informações do solo, posteriormente eram enviadas ao Arduino que por sua vez monitorava uma bomba hidráulica responsável por irrigar o solo supervisionado pelo sensor. Depois de alguns testes efetuados com o protótipo ficou comprovado o poder de processamento do Arduino e a precisão na coleta de dados processados pelo sensor.

Palavras-chave: Arduino; Sistema de irrigação; uso de sensores; irrigação automatizada localizada.

\section{INTRODUÇÃO}

Segundo Testezlaf (2011), desde a pré-história, o homem vem empregando o desvio de águas para irrigar suas plantações. Tem baseado em técnicas de desvios de águas que novas áreas, como regiões áridas e semiáridas, foram habitadas e cultivadas.

Hoje em dia, o uso da tecnologia está cada vez mais existente no cotidiano da vida humana. O crescimento de alternativas que possibilitam a aplicação da irrigação na agricultura familiar facilita a expansão da produção e a diminuição do êxodo rural (NASCIMENTO, 2006).

Guimarães (2011, p.11), por sua vez, afirma que: entre os sistemas de grande importância, se destaca a irrigação, capaz de fornecer um elemento imprescindível para a planta.

Porém, fazer a irrigação de um plantio não é tão fácil, pois é necessário determinar quando irrigar e a quantidade de água que se deve empregar. A aplicação de um sistema de irrigação automatizado diminui não só falhas humanas, como também o consumo de insumos e o custo de produção.

Segundo Guimarães (2011, p. 12), "a irrigação moderna é bastante avançada e possui variados tipos de automação, entretanto o pequeno e médio agricultor, nem sempre tem total acesso a essas tecnologias, seja por problemas financeiros ou por falta de conhecimento".

O desenvolvimento de um sistema de irrigação automatizado, localizado, e de baixo custo, 
não é direcionado somente para a agricultura, casas que contêm jardins também necessitam de um sistema de irrigação. Após pesquisas sobre as tecnologias disponíveis no mercado, voltadas para a automatização da irrigação no plantio, foi escolhido o Arduino. Ele é capaz de desenvolver equipamentos eletrônicos de baixo custo capazes de realizar as mesmas funções que equipamentos de alta tecnologia.

Dentro desse contexto, o presente estudo possui o objetivo desenvolver um protótipo de baixo custo que atenda a todo público que utiliza a irrigação.

Para isso, será utilizado o método de irrigação localizada automatizado, empregando a plataforma do Arduino, buscado oferecer, através do uso da tecnologia, água na medida certa para as plantas, evitando que contem apenas com o regime de chuvas ou dependam de cuidados constantens e precisos dos homens. O sensor tem a função de realizar uma leitura das dimensões físicas do local monitorado e as enviar ao Arduino, obtendo retorno das variáveis. Com isso, o Arduino executa as ações escolhidas na implantação do sistema e, dessa forma, através de uma bomba hidráulica ligada ao Arduino é possível preservar sempre a umidade do solo.

\section{REFERENCIAL TEÓRICO}

\subsection{Automação}

A automação é uma caracterização e um agrupamento de técnicas por intermédio das quais se fazem ativos capazes de operar com ótima eficiência pelo emprego de informações ganhadas do meio sobre o qual exercem (MORAES; CASTRUCCI, 2007). E o processo dessa tecnologia é completado com a atuação do ser humano.

Para Marcal, Guimaraes e Resende (2013) automação compreende a atuação de dispositivos mecânicos ou elétricos para facilitar e executar algumas tarefas e tencionam ampliar a eficiência e a segurança na operação. A automação está apresentando novas tecnologias de ponta, empresas dos mais diferentes ramos de mercado estão aderindo a este novo conceito procurando encurtar seus processos. A diminuição de custos e eliminação do desperdício concebido é a finalidade de todas as empresas e a automação é vista como uma das indispensáveis formas para alcançar esse objetivo.

Ou ainda, automação é uma junção de técnicas mediante às quais se confeccionam sistemas. Onde, se emprega um programa de instruções agrupado a um sistema de controle que realizara as instruções, formado por três elementos: energia para finalizar os processos e operar o sistema; programa de orientações para conduzir os processos e um sistema que controle e opere as instruções. Isto é, sistemas de produção automatizados atuam sobre o produto físico. Realizam operações como, processamento, montagem, inspeção, e gerenciamento de materiais. Determinam-se automatizados pelo fato de desempenhar suas operações em um nível menor de contribuição humana se confrontado ao processo manual (GROOVER, 2011).

\subsection{Irrigação}

Irrigação pode ser definida de diferentes formas, porém todas com o mesmo objetivo. Para Testezlaf (2001) irrigação é o uso de técnicas, formas ou meios utilizados para aplicar água artificialmente às plantas, procurando satisfazer suas necessidades e visando a produção ideal para o seu usuário. Já Mello \& Silva (2006) define irrigação como sendo a aplicação artificial de água no solo, em quantidades adequadas, visando proporcionar a umidade adequada ao desenvolvimento a fim de suprir a falta ou a má distribuição das chuvas. Apesar de serem 
definições diferentes, ambas se referenciam à forma de distribuição da água para manutenção das plantações.

Em regiões desfavorecidas climaticamente, como irregularidades pluviométricas e indisponibilidade hídrica, a irrigação tornou-se fundamental para o desenvolvimento socioeconômico e até cultural, podendo até aumentar a lucratividade em regiões onde agricultura já se tornou uma tradição (TESTEZLAF, 2011).

Com o aumento demográfico, e o êxodo rural, houve consequentemente o crescimento da necessidade dos recursos hídricos, no setor industrial com a necessidade de investimento em usinas hidroelétricas.Existem quatro tipos de irrigação: Irrigação por aspersão, Irrigação localizada ou microirrigação, Irrigação por superfície, Irrigação subterrânea ou subirrigação. Este artigo retrata a irrigação localizada onde o sistema em que a água é aplicada em alta frequência e baixo volume, sobre ou abaixo da superfície do solo, conservando com alto grau de umidade um pequeno volume de solo que comporta o sistema radicular das plantas (FRIZZONE, 2013).

Principais vantagens: maior produção por unidade de área; consome uma menor quantidade de água e energia; verticaliza a produção; impacto ambiental baixo; produção sustentável. Principais desvantagens: os custos de instalação e operação também são maiores que o sistema por superfície; tipo de sistema de irrigação que corre risco de entupir e requer mão de obra especializa, apesar de também ser pouca (AGROVALE, 2013).

A fim de acabar com a preocupação com a rega, surge então a irrigação automatizada, que nada mais é do que um sistema em que culturas, jardins, são irrigados em dias e horários préprogramados, com a duração de tempo determinado para atender às necessidades específicas de cada área e do tipo de vegetação (FRIZZONE, 2011). Existem inúmeras vantagens para se utilizar os sistemas de automação na irrigação, que estão relacionados do ponto de vista econômico e benefícios para a implantação (GORNAT E SILVA, 1990).

\subsection{Protótipo}

Os Protótipos podem ser compreendidos como arquiteturas funcionais construídas a partir de procedimentos preliminares para simular a aparência e a serventia de um software a ser confeccionado, ainda que de forma incompleta. Através de um protótipo, os futuros usuários do software, bem como aqueles que irão desenvolvê-lo, serão capazes de interagir, classificar, modificar e aprovar as características mais importantes da interface e da funcionalidade da aplicação.

\section{MATERIAIS E MÉTODOS}

O presente projeto foi desenvolvido pelos alunos da FIC - Faculdades Integradas de Cataguases, no período entre 01/03/2019 a 30/05/2019, em um sítio que se localiza em um município próximo ao Trevo de Camargo - MG.

Os métodos de pesquisas utilizados foram: pesquisa exploratória, que, segundo Gil (2010), tem o propósito de se familiarizar com o problema, buscando maior explicação, deixando mais claro e ainda elaborar hipóteses. Tem um planejamento bastante flexível, pois interessa considerar os mais variados aspectos relativos ao fenômeno estudado. Através da pesquisa exploratória, é possível obter explicação dos fenômenos que inicialmente não seriam aceitos por outros pesquisadores, mesmo com todas as evidências fornecidas, além de descobrir novos fenômenos e 
formular novas idéias e hipóteses.

Foi utilizada a pesquisa bibliográfica para embasar teoricamente o projeto, objetivando reunir informações e dados que serviram de base para a construção da investigação proposta a partir do tema aqui abordado. Com isso, foi traçado um histórico sobre o objeto de estudo, auxiliando na identificação de novas abordagens sobre o assunto. A pesquisa bibliográfica consistiu na coleta de obras de diversos autores, abrangendo livros, artigos e materiais disponíveis na internet, em bases de dados como SciELO e Google Acadêmico. Após a seleção do material, o mesmo foi lido, analisado e interpretado. Foram utiilizadas anotações sobre os conteúdos mais importantes, sendo usados como fundamentação teórica.

Na elaboração do projeto utilizou-se o método de irrigação localizada, onde a água é colocada diretamente no local desejado e com uma alta frequência e pequenas intensidades.

No processo da irrigação localizada, a água é distribuída por um tubo, com baixa pressão, e os emissores são fixados na tubulação do solo ou enterrados, seguindo o padrão do plantio. Isto porque a quantidade de água adequada para o melhor desenvolvimento de uma planta varia de planta para planta. (PRÁ, 2009).

Para a elaboração do protótipo, foram usados os itens descritos na Tabela 01, seguindo os passos descritos abaixo da mesma.

Tabela 01 - Especificações dos Componentes Eletrônicos

\begin{tabular}{|c|c|c|}
\hline \multicolumn{3}{|c|}{ ESPECIFICAÇÕES DOS COMPONENTES ELETRÔNICOS } \\
\hline ITENS & MODELO & QUANTIDADE \\
\hline $\begin{array}{c}\text { Sensor de umidade } \\
\text { (Higrômetro) }\end{array}$ & A080 & 1 \\
\hline $\begin{array}{c}\text { Microcontrolador } \\
\text { Placa de Arduino } \\
\text { Uno R3) }\end{array}$ & ATmega328 & 1 \\
\hline $\begin{array}{c}\text { Placa Relé } \\
\text { Bomba D'água }\end{array}$ & Triger & 1 \\
\hline Lâmpada Led & AD-16-22DR (FAB. JNG) & 2 \\
\hline Gravador UsB & $2.0 \mathrm{~A} / \mathrm{b}$ & 1 \\
\hline
\end{tabular}

Fonte: Próprios autores (2019)

Depois de verificar cada componente, começou sua integração no projeto.

$1^{\circ}$ Passo: Foi utilizada a linguagem $\mathrm{C}++$ (com pequenas modificações) que se encontra no apêndice. Foi gravado no microcontrolador por meio do gravador UsB e logo em seguido foi configurado o microcontrolador. Com o micro controlador configurado e já gravado conectou se 
então a válvula de solenoide e o sensor de umidade do solo ao pino de saída.

$2^{\mathbf{0}}$ Passo: $\mathrm{O}$ sensor ligado à porta analógica $\mathrm{A} 0$, detecta a umidade do solo e encaminha para a placa Arduino.

$3^{\circ}$ Passo: Ao obter as informações do sensor o microcontrolador do Arduino executa as informações definidas na programação. Remete em tempo real o percentual de umidade do solo, conforme a programação definida, se o percentual de entrada for inferior a 50\% de umidade, é enviado um sinal para o rele, que atua a bomba hidráulica e aciona a lâmpada Verde, irrigando o solo.

$4^{\mathbf{0}}$ Passo: No começo do processo de irrigação, a bomba não será desligada, até atingir $70 \%$ da umidade do solo.

$5^{\circ}$ Passo: Logo após o solo obter $70 \%$ de umidade, irá desarmar a bomba e a lâmpada verde e a lâmpada vermelha irão atuar, indicando que o processo de irrigação foi finalizado e retorna ao Passo 2. O programa compilado completo encontra-se no apêndice A desse trabalho.

\section{RESULTADOS E DISCUSSÕES}

Finalizadas as etapas de desenvolvimento, iniciou-se a instalação de todos os componentes que fazem parte do sistema projetado. Após a instalação dos componentes, efetuamos a montagem do protótipo.

A Figura 01 ilustra o projeto montado, com todos os dispositivos interligados e alimentados, abrangendo a placa e os dispositivos ligados aos pinos do microcontrolador.

Figura 01 - Projeto montado com os dispositivos interligados e alimentados

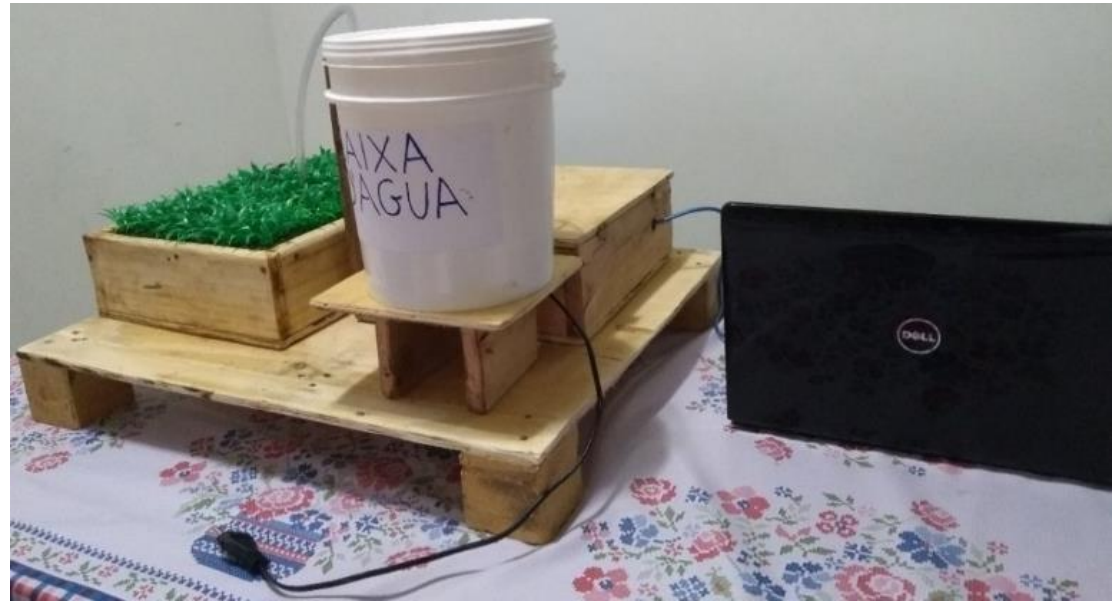

Fonte: Próprios autores (2019)

Com o sistema já operando, foi possível visualizar que o microcontrolador leu valores confiáveis do sensor e foi possível medir se o solo estava ou não no nível de umidade esperado e quando não estava, acionou a válvula de solenoide como previsto. $\mathrm{O}$ código foi configurado e inserido no microprocessador do Arduino, que fez as leituras dos sinais elétricos do sensor de umidade do solo empregado nesse projeto, liberando os sinais à atuação do relé sempre que a intensidade do sinal atingir os níveis programados. Assim, o fluxo de água será liberado sempre que o sinal de entrada atingir um valor programado. 
Figura 02 - Lâmpada verde atuada

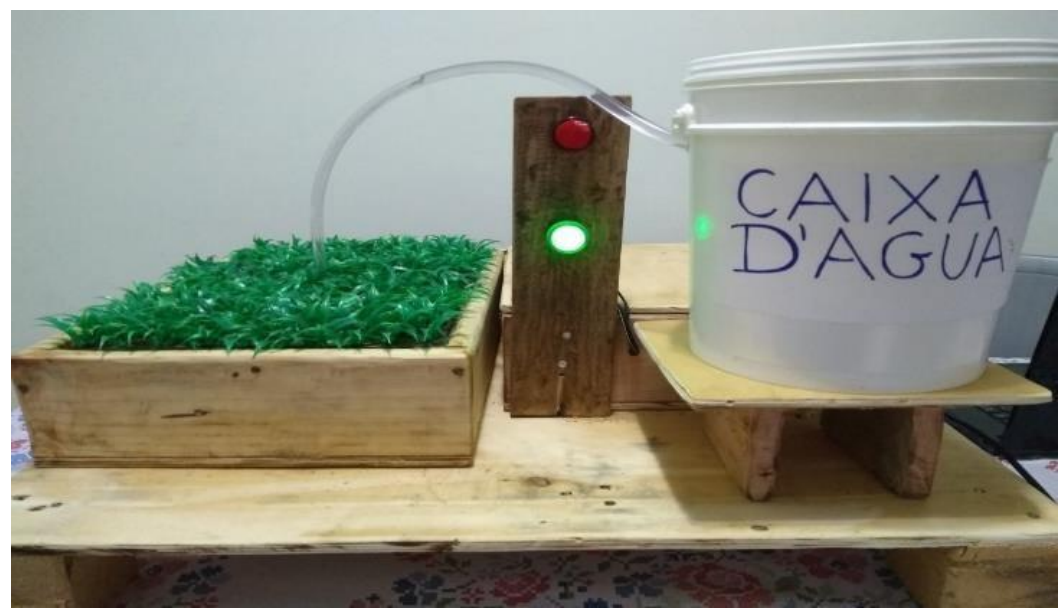

Fonte: Próprios autores (2019)

Conforme demonstrado na Figura 02, a lâmpada verde foi atuada, visto que o microcontrolador executou corretamente as informações do sensor, apontando o percentual de umidade do solo, conforme foi estabelecido pela programação. Com isso, a bomba hidráulica foi atuada, acionando a lâmpada verde e iniciando o processo de irrigação do solo. É importante salientar que o sensor utiliza sondas que passam a corrente através do solo e, assim, torna possível a leitura da resistência para saber o nível de umidade. Quanto maior for a quantidade de água no solo, melhor será a condução da eletricidade, gerando menos resistência. Quando o solo está seco, há a necessidade de condução da eletricidade, ocasionando maior resistência.

Dessa forma, com o valor maior que 160 (cento e sessenta), previamente definido no programa do sistema de irrigação, quando ele estiver acima do nível pré-estabelecido, o sistema acionou a bomba d'água e a lâmpada verde foi atuada, indicando que está acontecendo o processo de irrigação no solo.

Figura 03 - Lâmpada vermelha atuada



Fonte: Próprios autores (2019) 
A Figura 03 ilustra a lâmpada vermelha atuada, demonstrando que terminou o processo de irrigação, voltando ao sensor ligado à porta analógica e, assim, retornando para a detecção da umidade do solo, que voltará a ser encaminhada para a placa. Dessa forma, com o valor menor que 150 (cento e cinquenta), previamente definido no programa do sistema de irrigação, quando ele estiver abaixo do nível pré-estabelecido, o sistema desarmou a bomba d'água e a lâmpada vermelha foi atuada, indicando que o solo já atingiu a umidade estabelecida pelo programa do Arduino.

\section{CONSIDERAÇÕES FINAIS}

A partir da análise, na qual foram verificados vários aspectos que caracterizam o sistema de irrigação, foi possível obter um contato maior com um tipo de automação localizada aplicada. Notou-se que o funcionamento do sistema se dá de maneira simples e que o princípio se mantém constante em todas as situações para irrigação, o que pode variar é o investimento nos equipamentos e implementos conforme a necessidade de cada projeto.

A proposta da criação do protótipo foi a confecção de um sistema de irrigação localizada automatizado que utilizasse um sensor de umidade do solo e que as lâmpadas sinalizassem quando estivesse irrigando ou não para melhor visualização na hora de cultivar seu plantio.

Foi inserido um protótipo para o sistema, analisando problemas reais e considerando algumas variáveis, por exemplo: clima, solo e outros que foram eliminados durante a construção do projeto. Foi possível observar a exatidão do sensor, a capacidade de processamento do Arduino, posteriormente foi testado, com a utilização de mais sensores para que possa ser feita uma média da umidade de toda área monitorada.

O projeto abordou diversas áreas da tecnologia, tais como, eletrônica, simulação, programação, montagem e testes do circuito com o objetivo de obter uma medida do solo.

A escolha de um projeto que utiliza um sensor simples e que aceita uma leitura compatível com a realidade, o acionamento de válvula solenoide, a simulação do projeto, acionamento e a construção do protótipo, constituiu etapas concluídas com sucesso

\section{REFERÊNCIAS BIBLIOGRAFICAS}

AGROVALE. Métodos de irrigação. 2013. Disponível em:manejo-de-agua-e-solo-nos-perimetrosirrigados/apresentacao-8-agrovale-profo-vinicius-parte2.pdf $+\& c d=1 \&$ hl=pt-BR\&ct=clnk\&gl=br $>$. Acesso em: Mar. 2019.

ARDUINO. Arduino. Disponível em: <https://www.arduino.cc/>. Acesso em: Maio de 2019.

FRIZZONE, José Antônio. Irrigação localizada. 2013. Disponível em: https://docplayer.com.br/13630752Irrigacao-jose-antonio-frizzone-frizzone-esalq-usp-br.html Acesso em: fev. 2019.

FRIZZONE, José Antônio. Os métodos de irrigação. 2011. Disponível em: http://www.leb.esalq.usp.br/leb/disciplinas/Frizzone/LEB_1571/TEXTO_COMPLEMENTAR_1__METODOS_ DE_IRRIGACAO.pdf. Acesso em: Jan. 2019.

GUIMARÃES, Vinícius Galvão; Automação e monitoramento de sistema de irrigação na agricultura, Trabalho de Graduação, Engenharia Mecatrônica, Universidade de Brasília, 2011, p 11,12.

GIL, Antonio Carlos. Como Elaborar Projetos de Pesquisa. 5.ed. São Paulo: Atlas, 2010.

GORNAT, B.; SILVA, W. L. C. Sistemas de Controle e Automatização da Irrigação. ITEM - Irrigação e Tecnologia Moderna. ABID, Brasília, DF, V.41, abril, 1990.

GROOVER, Mikell P. Automação industrial e sistemas de manufatura. São Paulo: Pearson Prentice, 2011. MARCAL, Leandro Flor; GUIMARAES, Marco Paulo; RESENDE, André Alves. Automatização de uma termoformadora visando melhorias no processo produtivo de uma empresa fabricante de peças termoplásticas 
para o setor automobilístico. $2013 . \quad$ Disponível em: http://www.abepro.org.br/biblioteca/enegep2013_TN_STO_177_013_22735.pdf. Acesso em: 21 abril 2019.

MELLO, Jorge L. P; SILVA, Leonardo D. B. Irrigação. 637 p. Apostila. 2006. UFRRJ.

MCROBERTS, Michael. Arduino básico. 1 ed. São Paulo: Novatec, 2011

MORAES, Cícero Couto; CASTRUCCI, Plínio de Ladro. Engenharia de automação industrial. 2007. $2^{\text {a }}$ Edição. Disponível em: file:///C:/ Users/ Usuário/ Downloads/ Engenharia\%20de\%20Automacao\% 20Industrial $\% 202 \% 2$ 0ed\%20-\%20Moraes\%20\&\%20Castrucci.pdf. Acesso em: abril 2019.

NASCIMENTO, J. M. S. Desenvolvimento e avaliação hidráulica de um sistema de gotejamento por gravidade para pequenas propriedades. 2006. 79f. Dissertação (Mestrado em Engenharia Agrícola), Universidade Federal de Lavras, Lavras.

PRÁ, Bruno Rover Dal. Desenvolvimento de sistema para controle de umidade de solo em pequenas propriedades rurais. 2009. 66 f. Trabalho de Conclusão de Curso Aprovado Como Requisito Para Obtenção do Grau de Mestre (Superior) - Curso de Pós-graduação em Desenvolvimento de Tecnologia (prodetec), Departamento de Prodetec.

PEARROW, M. Pearrow. Disponível em: http://www2.dbd.pucrio.br/pergamum/tesesabertas/0313143_06_cap_10.pdf., 2000. Disponível em: 2007. Acesso em: jun. 2019.

RODRIGUES, Lucas; SARTORI, Eliseu; GOUVEIA, Bruno. Introdução ao Arduino. Mato Grosso do Sul: Fundação Universidade Federal de Mato Grosso do Sul, 2012. 25 p.

RUBIN, J. Rubin. Disponível em: http://www2.dbd.puc-rio.br/pergamum/tesesabertas/0313143_06_cap_10.pdf , 1994. Disponível em: 2013. Acesso em: jun. 2019.

TESTEZLAF, Roberto. Irrigação: Métodos, Sistema e Aplicações. UEC. Faculdade de Engenharia Agrícola. Março, 2001.

TESTEZLAF, Roberto. Irrigação: Métodos, Sistema e Aplicações. UEC. Faculdade de Engenharia Agrícola. Março, 2011.

APÊNDICE A: O programa compilado completo para o Sistema de Irrigação

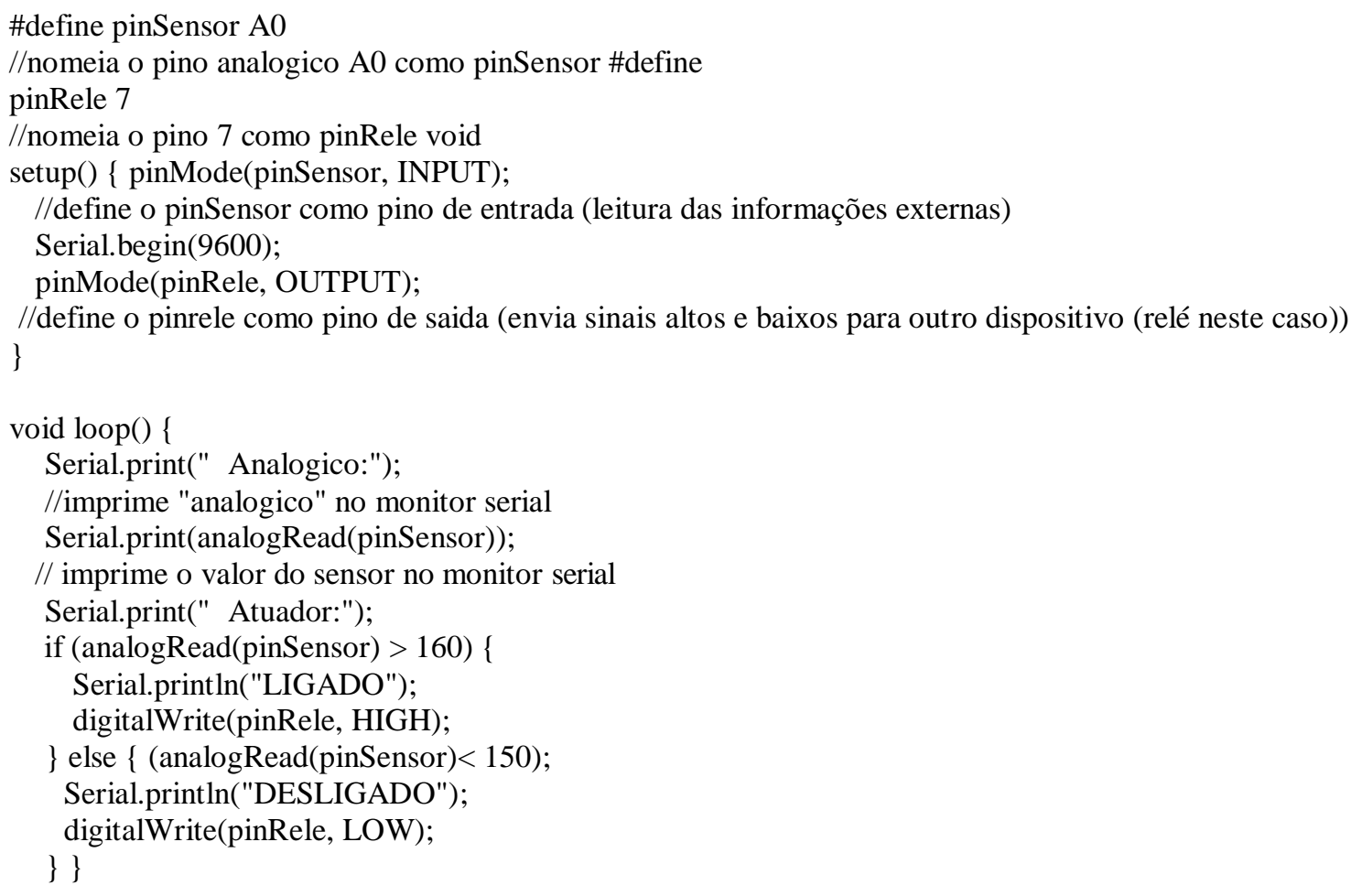

